\title{
ПОЛИТИЧЕСКАЯ ПСИХОЛОГИЯ
}

Аавынов С.В.

\section{ПОАИТИКО-ПСИХОАОГИЧЕСКИЙ ПРОФИАЬ ОППОЗИЦИОННОГО ПОАИТИЧЕСКОГО АЕЯТЕАЯ: ТЕОРЕТИКО-МЕТОАОАОГИЧЕСКИЕ АСПЕКТЫ}

\begin{abstract}
Аннотация. Статья посвящена теоретическим и методологическим аспектам применения в научно-исследовательской деятельности и при решении практических задач политического характера метода политико-психологического профилирования - одного из наиболее современных научных подходов, применяемых сегодня дяя изучения личности политических мидеров. Среди исследуемых при помощи данного метода политиков могут быть как представители официальных политических кругов, так и политики и общественные деятели оппозищионного направления. На «выходе» при их изучении должны быть определены те из их личностных характеристик, которые могут сыграть важную роль в экстремальных политических ситуачиях либо при приближении к ним. Применение системного подхода в качестве основы дяя теоретико-методологического обоснования политико-психологчческого профилирования позволяет «разложить» указанный метод на совокупность конкретных исследовательских подходов и приемов, что дает возможность впоследствии наиболее эффективно использовать данный метод при решении научных и практических задач. Аоказано, что перечень значимых мичностных характеристик оппозиционного общественного деятеля, получаемый на основе и при помощи разработанного алгоритма, наиболее эффективен дяя понимания и оченки его (деятеля) протестного потенциала. Показано, что наибольшая эффективность политико-психологического профилирования будет достигаться при применении таких критериев дистантной оценки личности оппозиционера, как если бы он мично принимал участие в тестировании самого себл. Вылвлены мичностные характеристики, особенно ярко выраженные у политических деятелей в периоды преодоления внешнеполитических кризисов.
\end{abstract}




\section{ПОАИТИКА И ОБЩЕСТВО • $9(141) \cdot 2016$}

Ключевые слова: дистантная, оченка, мидер, межличностное взаимодействие, политический профиль, методология, оппозиционер, политический деятель, политический, портрет.

Abstract. This article is dedicated to the theoretical and methodological aspects of implementation of the method of political-psychological profiling in scientific-research activity, as well as solution of practical tasks of political nature. Such method is one of the most recent scientific approaches towards the examination of the personality of political leaders. Among the subjected to this method politicians, can be the representatives of the official political circles, as well as politicians and public figures of the oppositional direction. Such research must determine the personal qualities, which can play an essential role in the urgent political situations. It is a proven fact that the list of most important personal characteristics of the oppositional political actor, acquired based or with the help of the developed algorithm, is most efficient for understanding and estimation of his protest potential. It is demonstrated that the highest efficiency of the political-psychological profiling can be achieved by means of application of such criteria in distant assessment of the persona of the opponent, as if he personally participated in the testing of himself. The author detects the personal qualities, which manifest among the political figures during the periods of overcoming the political crises.

Key words: distant, assessment, leader, interpersonal relations, political profile, methodology, opponent, political actor, political portrait.

K ак научный метод исследования, политико-психологическое профикирование направ ено на Аиагностику и прогнозирование поведения политического деятеля, анализ стратегий и стиля его межмичностных взаимодействий. Поэтому политико-психологический профимь политического мидера на практике преАстает как совокупность результатов измерения уровня выраженности таких качеств мичности помитика, которые явцяются значимыми Аля Аостижения им своих политических целей и заАач.

ОАнако, чтобы исследовать политика таким образом, следует решить Аве исследовательские задачи.

Первая: выбор метода Аля составмения перечня значимых Аля Аостижения цели политико-психологического профилирования мичностных характеристик политического деятеля. Вторая: выбор критериев Аля построения шкамы и выполнения оценки мичностных характеристик из полученного при решении первой задачи перечня. Отметим также, что эффективность решения этих задач определяется наличием неразрывной связи между выбранными мичностными свойствами политика и политической реальностью. КажАое мичностное свойство политики Аолжно оказывать непосреАственное влияние на его политические решения и заявления, то есть на все его политическое поведение в целом.

Первым направлением явмяется создание целостной биографии политического Аеятеля, основанной на психоанализе его мичности и политического поведения. Целью психобиографического описания явмяется исслеАование особенностей формирования мичности, поиск неклинических патологических черт и влияния их на политические решения и деятельность объекта исследования. Этот подхоА позволяет выявить причинно-слеАственные связи формирования и функционирования эмоциональной и мотивационной сферы мичности политического Аеятемя.

Вторым направлением является выявление, измерение и оценка выраженности мичностных черт политика, определяющих его политическую Аеятельность. Особенностью этого Подхода явмяется определение тех мичностных характеристик, Амя которых заданы соответствующие критерии в проведенных исследованиях. Такой метод также позволяет не только изучать отАельного Политика, но и ПровоАить сравнение Аичностей нескольких политиков, что становится возможным благодаря установленным количественным результатам измерения кичностных характеристик.

Третьим направлением является создание интегративной моАеми мичности политика на 
основе Аичностных характеристик и законов их взаимодействия и влияния на политическое поведение. Этот метод особенно ценен и довольно сложен, поскольку позволяет установить взаимосвязь межАу провоАимой Политикой и внутренним Я самого политика, а также этот метоА позволяет сравнивать мичности политиков. Кроме того, такой подхоА явмяется базой Аля созАания типологий политических Аеятелей по стилю их повеАения, принятия решений, стрессоустойчивости и т.А. в зависимости от цели конкретного исслеАования.

Все эти подходы также базируются на размичных мичностных теориях - от психоанакиза Ао материального Аетерминизма[1]. Еще оАним важным методологическим аспектом политикопсихологического профилирования является выбор межАу идеографическим и типологическим ПоАХоАом к анализу мичности политика. По нашему мнению, помитико-психологическое профилирование - как метод измерения мичностных свойств политического Аеятеля - базируется на идеографическом подходе, поскольку результатом измерения явмяется уникамьный результат, присущий конкретной, отАемьной взятой мичности. Кроме того, поскольку кажАая политическая ситуация уникальна, также уникальны и принимаемые в ее рамках политические решения, что определяет потребность в применении Аля составмения профимя политика такого подхода, который позволит учитывать все инАивиАуальные особенности его политического повеАения.

В исследованиях Е.В. Егоровой и В. А. Зорина отмечается необходимость при составмении политико-психологического профиля политического деятеля соблюАать ряА условий, а именно:

- политическая релевантность профиля, т. е. соответствие его тем реацьным политическим условиям, в которых Аействует политик;

- сопоставимость критериев Аля возможности сравнения кичностей разных политиков и сравнения мичности отАельного политика в разное время;

- применение идеографического подхода к составцению профимя;

- использование полного объема Аоступных Аанных;
- избегать сложной теоретико-научной психомогической терминологии, оперируя помитическими терминами [2].

Как известно, Аля политико-психологического профилирования необходимо опреде-

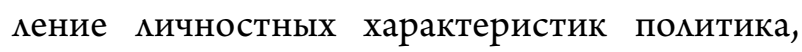
значимых в контексте решаемой практической задачи. Это определение Аолжно основываться на практическом, связанном с политической реальностью, поАтвержАении значимости выбранных характеристик Аля Аостижения поставленной цели. Отметим, что в контек-

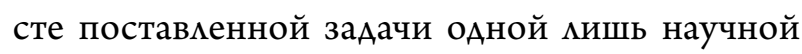
интуиции исследователя недостаточно. Концепция «зАравого смысла» также не является Аостаточным обоснованием Аля выбора значимых Аля политика мичностных черт, поскольку такой поАхоА ограничивается очевидными факторами, но не учитывает значимость неочевиАных явлений, влияние которых на результаты политической Аеятельности может быть весьма существенным. «ЗАравый смысл» в Аанном случае является скорее критерием алекватности и соответствия полученных результатов при составмении политико-психологического профимя политика политической реальности, т. е. выполняет оценочную функцию.

В контексте изучения мичности политика, с учетом недоступности контактных методов обследования и изучения объекта исследования, имеется, по нашему мнению, три принципиацьно отличных подхода к формированию перечня значимых мичностных характеристик и построению политико-психологического профиця политического деятемя.

Целью кажАого их трех ПоАходов является получение полного перечня мичностных характеристик политического Аеятеля и выявление тех из них, которые оказывают значимое вмияние на политическую Аеятельность.

Первым из обозначенных подходов явмяется организация и проведение контактных исследований с мицами, повеАение которых может быть приравнено к поведению политического деятеля. Такое исслеАование преАполагает воспроизведение политической Аеятельности в группе иссле-

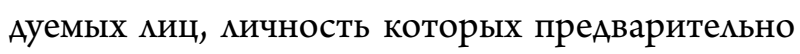
оценивается по опреАеленной психологической 


\section{ПОАИТИКА И ОБЩЕСТВО • $9(141) \cdot 2016$}

методике. Аля проведения исследования созАаются условия, соответствующие размичным политическим ситуациям, подразумевающим участие политиков с опреАеленными целями и особенностями поведения. Оценка результатов исследования Аолжна выполняться экспертамиполитологами и политическими психологами. Таким образом, Амя построения перечня значимых мичностных характеристик политического Аеятеля используются слеАующие результаты исслеАования: экспертная оценка поведения исследуемых миц и результаты мичностного тестирования респондентов.

Вторым путем явмяется изучение первичных Аанных о политических деятелях. В контексте задач политической психологии это - исслеАование мичностей политиков Аистантными методами с цемью выявления их значимых Аля политико-психологического профилирования специфических мичностных характеристик. В самом общем виде этот подхоА преАполагает контент-анализ, интент-анамиз и психобиографические исследования, в результате чего составляется перечень мичностных характеристик, влияющих на политическую деятельность политика и Аостижение им конкретных помитических целей в опреАеленных условиях.

Третьим путем явцяется анациз вторичных Аанных по резумьтатам уже проведенных и поАтвержАенных мнением веАущих экспертов исследований мичностей политических деятелей. Фактически, третий поАхоА преАставмяет собой аналитическую часть второго подхода, т. е. на основании резумьтатов уже выполненных контент- и интент-анализа, психобиографических исследований выполняется структуризация и анализ значимых Аля политической Аеятельности мичностных характеристик.

Все перечисленные подходы имеют как преимущества, так и недостатки, поэтому выбор подхода Аолжен осуществляться на основании оценки временных, научных, трудовых и финансовых ресурсов Аля выполнения политико-психомогического профилирования.

Первый подход имеет наименьшую Аостоверность, поскольку моделирование политической ситуации не может вкмючить в себя все факторы, определяющие ее специфику. Также моделирование политической ситуации преАполагает наибольшие временные и финансовые затраты.

Второй подхоА преАставмяется наиболее Аостоверным из трех, поскомьку позволяет выполнить анализ мичностей политиков в наибомее полном соответствии с поставценной целью, избегая теоретических и практических Аопущений, аналогий и приближений, Аействуя строго в рамках контекста политической реальности. С Аругой стороны, второй подхоА сопряжен с высокой трудоемкостью, поскольку требуется поиск и обработка значительного объема информации по кажАому политику, преАставляющему ценность Аля анализа и изучения. К тому же Аоступ к информации может быть ограничен как нормативно-правовыми актами, так и рядом иных причин, связанных с закрытостью политической сферы Аля анализа.

Третий поАход преАставмяется наиболее экономичным с точки зрения трудозатрат на его реализацию и обладающим высокой Аостоверностью, поскольку анализ строится на изначально Аостоверных результатах, полученных состоявшимися и уважаемыми в научной среде политологами и политическим психологами и получивших общенаучное признание. Поэтому Амя выполнения политико-психологического профилирования как метода, позволяющего получить оценку состояния политика в конкретной ситуации Амя решения конкретной практической заАачи в условиях ограниченного времени, преАставляется наиболее ПОАХОАящим ТРеТИй ПОАХОА.

С учетом отмеченных позитивных и негативных свойств рассмотренных подходов, наиболее эффективным преАставляется слеАующий алгоритм выбора подхода к получению перечня значимых мичностных характеристик помитического деятемя:

1. Историографический анализ проведенных политологических исследований и систематизация составленных ранее портретов и профилей политических Аеятекей;

2. Оценка Аостаточности и полноты свеАений в проведенных исследованиях Аля формирования перечня значимых мичностных характеристик политического Аеятеля. Если этих сведений Аостаточно, то следует выбрать 
третий поАхоА. Если свеАений неАостаточно, следует переход к пункту 3);

3. Оценка достаточности доступных материамов Аля самостоятельного выполнения контент-, интент- и психобиографического анаАиза Аичностей политиков. Если материалов Аостаточно, то слеАует выбрать второй поАхоА. Если недостаточно, то следует выбрать первый подхоА.

Обратимся теперь ко второй методологической задаче политико-психологического профилирования, а именно - к методологии выработки критериев оценки выбранных значимых личностных характеристик политика. Отметим, что ААя Аостижения наибольшей эффективности политико-психологического профилирования необходимо стремиться к составлению таких критериев Аистантной оценки мичности политика, как если бы он сам мично принимал участие в тестировании.

Как неоднократно отмечалось ранее, к АИстантным методам изучения мичности политического деятеля относятся контент-анализ, интентанализ и психобиографический поАХОА и Ар.

ПреАполагается выполнение синтаксического, грамматического и мексического контентанализа и психолингвистический анамиз когнитивной простоты/сложности. В текстах речей политиков оцениваются скмонность к употреблению определенных речевых оборотов, образность текста, уровень абстрактности и конкретности речи, глубина, сложность, оригинальность высказываний. ГАавной единицей Аистантного анализа мичности является дескриптор, что обуславливает необходимость тщательного отбора таких мексико-грамматических явлений, количественное распределение которых можно использовать при построении шкал, применяемых Аля измерения индивидуально-типологических особенностей мичности политика[3].

Аостоверность и эффективность психолингвистического анализа при выявлении особенностей и оценки выраженности Аругих мичностных характеристик политического деятеля в его вербальной деятельности не вызывает сомнения.

Остановимся на более подробном рассмотрении метода контент-анализа и применяемых в его рамках психолингвистических подходов.
Концепции и количественного, и качественного анализа строятся на преАставлении о том, что языковые формы, которые принимает речь исследуемого политика, явмяются проекцией его мичности, поэтому изучение речевых форм, оборотов, Ааже интонаций явцяется Аостоверным и информативным источником сведений о Аичности политического деятеля.

Разграничение контент-анализа на количественный и качественный подходы преАставмяется Аля целей политико-психологического профилирования недостаточно эффективным. Так, прямой подсчет количества заданных речевых форм в текстах выступления политиков может приводить к искаженной интерпретации личностных свойств, поскольку не учитывается контекст и возможны такие комбинации смов, особенно при использовании многократного отрицания, при которых их смысл в тексте и смысл в подсчете могут быть противоположны. Кроме того, отказ от качественного анализа не позвомяет оценивать ни рациональность политика, ни убедительность его аргументов.

ПрежАе чем перейти к результатам анализа и опредемению значимых Аля оппозиционного Аеятеля мичностных характеристик, образующих его политико-психологический профиль, сАелаем оАно Аопущение, не противоречащее системному и могическому принципам. Примем, что деятельность политического Аеятемя, влияющего на внешнюю политику государства, имеет признаки, схожие с деятельностью оппозиционного политика, а именно постоянное негативное воздействие внешней среды и необходимость преодолевать сопротивление политической системы. Оппозиционная деятельность подвергает осуществляющего ее политика рискам утраты свободы, общественного положения, статуса и Ааже жизни, что является непрерывно действующим на его мичность стрессовым фактором.

Также внешнеполитическая Аеятельность часто сопровожАается кризисными явлениями, что подвергает политика непрерывному стрессовому воздействию. Поэтому изучение кичности политика, осуществляющего внешнеполитическую деятельность, особенно в состоянии кризиса, явмяется Аостоверным источником (и примером) аля формирования перечня кичност- 
Иичностные характеристики помитика, выраженные в период политического кризиса

(составмено автором по материалам исследований Е.В. Егоровой,

В.А. Зорина, Н.В. Бушуевой, О.И. Ауминской, Е.Р. Аюльчак)

\begin{tabular}{|c|c|}
\hline Группа характеристик & Личностные характеристики \\
\hline Сила воли & $\begin{array}{l}\text { Стойкость } \\
\text { Мужество }\end{array}$ \\
\hline Смелость & $\begin{array}{l}\text { Решительность } \\
\text { Готовность к разумному риску } \\
\text { Готовность принять последствия политических решений и нести за них } \\
\text { ответственность }\end{array}$ \\
\hline $\begin{array}{l}\text { Рациональность и глубина } \\
\text { аналитического мышления }\end{array}$ & $\begin{array}{l}\text { Способность воспринимать рациональные аргументы } \\
\text { Способность генерировать рациональные аргументы } \\
\text { Способность понимать сущность политической проблемы } \\
\text { Способность просчитывать последствия политического решения }\end{array}$ \\
\hline Амбициозность & $\begin{array}{l}\text { Стремление к успеху } \\
\text { Стремление войти в историю } \\
\text { Стремление к материальному благосостоянию } \\
\text { Стремление доказать превосходство } \\
\end{array}$ \\
\hline Новаторство & $\begin{array}{l}\text { Способность генерировать новые идеи } \\
\text { Способность принимать новые идеи } \\
\text { Склонность к консервативным подходам } \\
\text { Отрицание новых идей }\end{array}$ \\
\hline Стремление к борьбе и риску & $\begin{array}{l}\text { Стремление к борьбе как процессу } \\
\text { Рискованность }\end{array}$ \\
\hline Непримиримость & $\begin{array}{l}\text { Полное неприятие противоречащих позиций } \\
\text { Ощущения нестабильности и опасности при реализации чужих позиций }\end{array}$ \\
\hline Доминантность & $\begin{array}{l}\text { Неприятие подчинения } \\
\text { Склонность к принуждению других к своей воли } \\
\text { Спонтанная способность к принуждению других к своей воле } \\
\text { Убежденность в собственной позиции }\end{array}$ \\
\hline Конфликтность & $\begin{array}{l}\text { Склонность рассматривать конфликт как метод решения политической } \\
\text { проблемы } \\
\text { Получение удовольствия от конфликта } \\
\text { Избегание конфликта }\end{array}$ \\
\hline Склонность к компромиссу & $\begin{array}{l}\text { Предпочтения компромисса как метода решения политической проблемы } \\
\text { Избегание конфликта } \\
\text { Удовлетворение от роли миротворца }\end{array}$ \\
\hline
\end{tabular}

ных характеристик оппозиционного помитического деятемя.

Нами были проанамизированы помитико-психологические профими четырнаАцати политиков, выполненные в многочисленных исследованиях ряла авторов (Е.В. Егоровой, В.А. Зорина, Н.В. Бушуевой, О.И. Ауминской, Е.Р. Аюльчак). В результате такого анализа выделены мичностные характеристики, особенно ярко выраженные у политических Аеятелей в периоды преодоления внешнеполитических кризисов или иного политического противостояния.

Обратим внимание, что выраженность этих характеристик определяет эффективность политической Аеятельности исследуе- мого субъекта, поэтому в перечне преАлагается группировка характеристик, вкмючающая как позитивные, так и негативные Аля политической Аеятельности их проявления. Помярность значений характеристик может быть основной Аля Аальнейшей выработки критериев и шкам их оценки.

Перечень мичностных характеристик политических Аеятелей и их группировка преАставлены в таблице.

В резумьтате анализа характеристик политико-психологического профикирования мичности политического милера можно оценить его (профимирование) как процеАуру выявмения значимого Аля решения конкретной практической политической заАачи совокупности 
перманентных и ситуативных мичностных характеристик политического мидера и их количественного измерения по заАанным критериям. Методология политико-психологического профилирования требует решения Авух заАач: выбора оснований Аля составмения перечня значимых мичностных характеристик и выбора критериев их оценки.

Сказанное, помимо всего прочего, означает, что существуют кмючевые сходства и размичия в методах политико-психологического портретирования и политико-психологического профимирования. Общим Аля них явмяются межАис- циплинарность и практическая направленность, наличие инвариант, необходимых Аля Аостижения цели исследовании, ограниченность в использовании контактных исследований мичности, преимущественное использование Аистантных ПоАходов К исслеАованию Аичности политического Аеятеля. ОАнако ключевым размичием явмяется целостное, качественное описание мичности политического деятеля при осуществлении портретирования и комичественное измерение уровня выраженности его опредеменных мичностных свойств при осуществлении профикирования.

\section{БИБАИОГРАФИЯ}

1. Егорова-Гантман Е.В. ИмиАж милера. М.: Знание, 1994. С. 256.

2. Зорин В.А. Психологические профили российских, украинских и белорусских политических мидеров // Политическое мидерство в Восточной Европе: Сборник научных трудов отАела Восточной Европы ИНИОН РАН. М., 2003. С. 17-24.

3. Щербакова Н.В. Прогнозирование политического поведения субъектов власти на основании психолингвистического анамиза когнитивных стилей / Психомогия власти. СПбГУ, 2004. С. 177-186.

4. Сулакшин С.С. Цивилизационный количественный российский профиль // Философия и культура. 2015. - 2. - C. 201 - 211. DOI: 10.7256/1999-2793.2015.2.13758.

\section{REFERENCES (TRANSLITERATED)}

1. Egorova-Gantman E.V. Imidzh lidera. M.: Znanie, 1994. S. 256.

2. Zorin V.A. Psikhologicheskie profili rossiiskikh, ukrainskikh i belorusskikh politicheskikh liderov // Politicheskoe liderstvo v Vostochnoi Evrope: Sbornik nauchnykh trudov otdela Vostochnoi Evropy INION RAN. M., 2003. S. 17-24.

3. Shcherbakova N.V. Prognozirovanie politicheskogo povedeniya sub"ektov vlasti na osnovanii psikholingvisticheskogo analiza kognitivnykh stilei // Psikhologiya vlasti. SPbGU, 2004. S. 177-186.

4. Sulakshin S.S. Tsivilizatsionnyi kolichestvennyi rossiiskii profil' // Filosofiya i kul'tura. - 2015. - 2. - C. 201 - 211. DOI: $10.7256 / 1999-2793.2015 .2 .13758$. 